\title{
The Effect of Sales and Evidence from Micro Data
}

\author{
Zi-Yi Guo $^{1} \&$ Yangxiaoteng Luo $^{2}$ \\ ${ }^{1}$ Corporate Model Risk Management Group, Wells Fargo Bank, N.A., 301 S College St, Charlotte, NC 28202, USA \\ ${ }^{2}$ Department of Finance, Kellstadt Graduate School of Business, Depaul University, 1 E. Jackson Blvd., Chicago, IL \\ 60604, USA \\ Correspondence: Zi-Yi Guo, Corporate Model Risk Management Group, Wells Fargo Bank, N.A., 301 S College St, \\ Charlotte, NC 28202, USA.
}

Received: March 29, 2017

Accepted: April 19, 2017

Online Published: May 8, 2017

doi:10.5430/rwe.v8n1p37

URL: https://doi.org/10.5430/rwe.v8n1p37

All views are those of the authors and do not necessarily reflect those of the organization to which the authors are affiliated.

\begin{abstract}
The concept of menu cost indicates that firms are facing a fixed menu cost when they want to change the nominal prices. However, the standard menu cost model is hardly to explain the observed facts from micro-level data, especially in terms of sales. In this paper, we investigate the effect of sales through a novel product-level dataset. There are at least three findings from our estimation results. First, we find that retail sales themselves, rather than price decreases, have a large effect on consumers' purchases. Second, consumers are more prices sensitive when the product is on sale than they are when the product is not on sale. Third, consumers are far more aware of price decreases than price increases.
\end{abstract}

Keywords: menu costs, consumers purchases, Heckman two-step estimation

JEL classifications: D01; D12; E00

\section{Introduction}

There is much literature focusing on the micro pricing facts. How do firms change their prices? The standard menu cost model tells us that firms want to change their nominal price so that the real price of their product always is at an optimal level. However they are facing a fixed menu cost each time they change nominal prices. Thus, they update their nominal prices when the benefits exceed the cost of changing prices. However, in Fabiani et al. (2005), managers who are in charge of setting prices are interviewed and asked to list the most important factors in price making process. They find that managers generally do not care about menu cost when changing prices. Most of the managers say that consumers' responses are the most important thing for their price policy.

Another issue about price changes is the effect of sales. Based on BLS's data, Nakamura and Steisson (2008) find that about one third of the price changes are due to sales. However, most literature in the micro pricing field takes the observations with sales as noises, and a standard way to treat the observations with sales is to exclude them in the analysis. In this paper, we try to separate the effect of sales from the effect of price decreases, although they often occur at the same time. Also, we are trying to test whether demand shows different patterns towards price increases and price decreases. There are at least three findings from our estimations. First, we find that retail sales themselves, rather than price decreases, have a large effect on consumers' purchases. Second, consumers are more prices sensitive when the product is on sale than they are when the product is not on sale. Third, consumers are far more aware of price decreases than price increases.

\section{Literature Review}

The traditional models explaining how firms change their prices are the $(\mathrm{S}, \mathrm{s})$ menu cost models, such as Barro (1972), Sheshinski and Weiss (1977), and Magnani, Gorry and Oprea (2016). They argue that the firm has a target real price, S. They want to change the nominal price with inflation so that the real price is always S. However, the firm is facing a fixed cost when changing prices, so it will not be economical for the firm to change their nominal price all the time. In the benchmark menu cost model, the optimal strategy for the firm is to set a lower bound of 
their real price s. So the real price decreases over time due to inflation, and when the real price hits the lower bound s, the firm will change the nominal price so as to make the real price back to $\mathrm{S}$.

An important variation of the classic (S, s) model is shown by Golosov and Lucas (2007). They construct a stochastic menu cost model with idiosyncratic shocks. Nakamura and Steisson (2008) compare the performance of the menu cost model without idiosyncratic shocks and the model with idiosyncratic shocks, and conclude that the model with idiosyncratic shocks is more consistent with the data. However, in their paper they also show that even the menu cost model with idiosyncratic shocks fails to plausibly explain some stylized facts of prices. For example, in menu cost model, the hazard rate of price changes should be increasing in the first few months, but data shows that the hazard rates are sharply deceasing in the first few months.

One defect of menu cost models is that those models can only have a partial equilibrium solution, and they always assume that the demand is a simple function of real price. Moreover, the price changes are mainly driven by the supply side. However, Fabiani et al. (2005) show that when managers adjust prices, the most important factor which they take into account is the demand. In other words, when modeling price changes, we cannot simply focus on the factors in the supply side as the menu cost models do. As for the demand side, Rotemberg (2008) summarizes all the evidences against the "law of demand", which says the quantity sold should purely be a function of price. Scholars find that less than half of the consumers can perfectly recall the prices 30 seconds after they pay, and only a few consumers can tell which prices are good deals if they are not allowed to compare. Moreover, he argues that people's consumption is affected by their emotions. Consumers tend not to purchase when they are afraid that they are paying too much after the consumption. Also, in Fabiani (2005) firm managers claim that the major concern is avoiding consumer antagonism. This fact also supports the idea that consumers' emotion affects their consumption.

Sales are very common in most of the grocery stores, and they can affect demand through several channels. First, the signal of "sales" can reduce the information asymmetry. Consumers think that they are not purchasing at a high price when they see the "sale" sign. In other words, sales eliminate the possibility of consumers' regret, and thus the consumption increases. Second, sales have a role of advertisement. Chevalier, Kashyap and Rossi (2003) show that "loss leader" model can correctly predict the correlation between demand and markup. They argue that sales are like advertisement and they will attract people to the stores. However, retail sales are little discussed in most of the existing literature on menu cost models, which just seek to fit the behavior of prices excluding sales (see, e.g., Golosov and Lucas, 2007). There are two categories of opinions that explain sales. First, one opinion is about the demand side. Some economists argue that sales arise because of price discrimination of retail outlets (Varian, 1980). Second, some other economists think the incentive of sales is from the supply side. Sales are used as a method for inventory management (Aguirregabiria, 1999). In this paper, we will make use both of the opinions of sales.

The remaining part of the paper is structured as follow. The second section describes the data and the econometric models that we use, and the third section shows the empirical results. The last section is the conclusion and discussion.

\section{Data and Methodology}

\subsection{Data Description}

Dominick's Finer Foods (DFF) is the second-largest supermarket chain in the Chicago metropolitan area; they have approximately 100 stores and a market share of approximately $25 \%$. Dominick's provided the University of Chicago Graduate School of Business with weekly store-level scanner data by UPC including: unit sales, retail price, profit margin (over the wholesale price), and a deal code indicating that the price reduction is accompanied by some sort of advertising (typically a feature ad or special shelf tag).

There are 11 categories of products in the dataset. We choose one brand of canned tuna that has the most observations in the DFF dataset. It fits the paper due to the following reasons. First, we are trying to eliminate the seasonality of transactions in the analysis, so those products with strong seasonal demand are not appropriate for this paper (e.g. Beer). Second, price elasticity is another issue. As we are focusing on the effect of sales on demand, the products that are very price inelastic (for example, butter, or toilet tissue) are not good objects to study as well. Third, we want to study the relationship between price and demand at a product level, instead of aggregating the quantity and building up some price index. If we aggregate the products, then the correlation between quantity sold and sales will be less clear. Fourth, the product of canned tuna has some nice features. For example, every brand has its own taste. If we assume people's taste does not frequently change, then we can say that people are loyal to certain brand. Hence we can partly eliminate substitution effect of prices: consumers will not switch to other band due to prices. Fifth, since we examine the data at the product level, missing data in this DFF dataset becomes a big problem. Thus, 
we just try to get as many observations as possible. The best-selling product's UPC number is 8660000033 , and the name is "BUM BEE/WATER CHK LI". It contains around 20,000 observations.

\subsection{Data Processing}

Before the regression, we process the data in the following procedures. First, we put a dummy variable of sales into this dataset. If the product in certain store at a certain week is on sale, then the dummy variable equals 1 . Otherwise it is 0 . It is natural for us to put the dummy denoting sales since this research is studying the role of sales. Also, we put two dummy variables which denote price increase and price decrease comparing with last week. Second, we put dummies into the data set. The first set of dummies is the store dummy. Different stores are located in different districts, and generally different districts are good indicators for people's income level. Therefore the store number dummy has correlation with the transactions. The second set of dummies is the week dummy. Week dummy could be considered as a proxy for the time-specific shocks, which may be relevant with the demand as well. The third set of dummies is the dummy for American public holidays. There may be "natural peak" of the demand at holidays. In total, we put three sets of about 450 dummy variables into the dataset. Third, we construct a variable of "unit cost" by making use of the variables of price and profit margin. The way we construct it is shown by Equation (3) in the model part in this section.

In sum, all the variables that may appear in my regressions are: move (quantity sold), log(price), sales dummy, store dummy, week dummy, and unit cost. Different stores have different time span of observations, but the total time range is 399 weeks. Therefore generally there are 93 stores and 399 weeks.

\subsection{Models}

The main regression equation is as follows:

$$
y_{1}=\beta x+\alpha y_{2}+u_{1},
$$

On the LHS, $y_{1}$ is the variable of move, or quantity sold. On the RHS, $x$ contains the variables of $\log$ (price), week dummy, and store dummy. $y_{2}$ is the dummy variable denoting sales. Hence in this regression equation, there are five factors affecting the demand: price, store specific shocks, time specific shocks, the "natural peak" in public holidays, and whether the item is on sale or not. The result of this regression is shown in Table 1.

One potential problem in this equation is that $y_{2}$ might be endogenous. Some unobserved factor will lead to both retail sales and high demand. For instance, at the holiday of Lent, people traditionally eat tuna, and stores always set their tuna "on sale" during that time. To take the potential endogeneity problem into account, we impose a typical two-step IV regression. The first step is a probit model with the following regression equation.

$$
y_{2}^{*}=\gamma x+\delta z+v_{2}
$$

Here on the LHS $y_{2}{ }^{*}$ is the latent variable. The sales dummy $y_{2}$ equals 1 if $y_{2}{ }^{*} \geq 0$; otherwise $y_{2}$ equals 0 . On the RHS, $x$ contains all the variables of $x$ in regression equation (1), and $z$ is the instrument variable. The instrument variable should be correlated with sales and uncorrelated with the demand. We use the unit cost of last period as an instrument of sales. On the one hand, unit cost should not be correlated with consumers' demand. On the other hand, unit cost is correlated with sales because sales are used as a method of inventory management. Unit cost of the product can reflect the cost of inventory, and the inventory cost is the main factor that affects the decisions of inventory management. When inventory cost is high, the unit price will be high, and the retailer may want to make a clearance sale. There is no such variable as unit cost in the dataset, but the DFF dataset provides the profit margin in each observation. Hence we construct the unit cost variable by the following equation.

$$
\text { unit cost }=(1-\text { profit margin }) \times \text { price. }
$$

The second step is to replace $y_{2}$ by $\hat{E}\left(y_{2}=1 \mid x, z\right)$ in regression (1) and run the OLS regression. The result of this IV regression is shown in Table 2.

Another concern is that there may be selection problem. On the one hand, quantity sold may increase because of sales. On the other hand, a high transaction amount may stimulate the store to set more sales. We will follow a standard Heckman two step estimation to estimate the marginal effect of price when the product is on sale, and the result is shown in Table 3. In the Heckman two-step estimation, the first step of probit regression will just follow equation (2), and the second step of OLS regression uses the following equation:

$$
y_{1}=\beta x+\varphi \quad \lambda+u_{2},
$$

where $x$ is the same as in other equations, and $\lambda$ is the inverse Mill's ratio. 
After controlling for the factor of retailer sales, we also want to know whether people have the same attitude when they face price increases and price decreases. Therefore, we conduct the following experiment. First, we obtain the residuals from the IV regression. Second, we regress the residuals on the dummies of price increases and price decreases. Finally, in order to test the robustness of the results in two subsamples: the subsample that the product is on sale, and the subsample that the product is not on sale.

\section{Empirical Results}

\subsection{OLS Model}

The result of the OLS model is shown in Table 1. We can see that price has a negative coefficient of -819.3664 , and sales dummy has a positive coefficient of 47.64138. Both of them are very significant. The signs of the two coefficients are consistent with our intuition. When price decreases, demand will increase. Also, when there is a sale, demand will increase as well. The coefficient of the dummy variable denoting sales is 47.64 . So basically, if the store flags the tuna product as "sale", its quantity sold will rise by 47.64 . This number looks very small. However, as there may be endogeneity problem and selection problem, the coefficients might be inconsistent.

Table 1. OLS regression

\begin{tabular}{lcccc}
\hline & coef & Standard Error & p-value & R-Square \\
\hline Log(price) & -819.36 & 12.43 & 0.00 & \multirow{2}{*}{0.18} \\
\cline { 1 - 4 } sales dummy & 47.64 & 5.37 & 0.00 & \\
\hline
\end{tabular}

OLS regression: $y_{1}=\beta x+\alpha y_{2}+u_{1}$

$y_{1}$ : move (quantity sold); $x: \log$ (price), store dummy, week dummy; $y_{2}:$ sales dummy.

\subsection{Instrument Variable Regression}

The first step is a probit model, and the variable of unit cost in last period is used as an instrument. The theory is that sales are partly due to inventory management. When inventory cost is too high, the retailer will want to clear their stock and make a sale. The unit cost can partly reflect the inventory cost. Hence according to the theory, the unit cost should be negatively correlated with the probability of making sales. The result of the probit model is shown in Panel A of Table 2. The result from the probit model is consistent with our intuition, as well as the theory. First, $\log ($ price) has a negative coefficient. The sign is reasonable, since sales are always correlated with lowering prices. Second, the probit regression shows that the unit cost in last period has a significant effect on the probability to make a sale. This confirms the prediction from the theory that sales are partly because of inventory management.

Panel B of Table 2 shows the result from the second step of the two-step IV regression. In this regression we use the predicted value of the sales dummy, or $\hat{E}\left(y_{2}=1 \mid x, z\right)$, to substitute $y_{2}$, the sales dummy. The result is amazingly different from what we get in Table 1 . The coefficient of the $\log$ (price) variable reduces to -387 , and the coefficient of the sales dummy rises to 739. Both of them are still very significant. Comparing with the result from the OLS estimation, we can see that the effect of sales is seriously underestimated. Also, the sharp difference between the two estimations shows that the endogeneity problem cannot be neglected.

However, another problem arises when we use $\hat{E}\left(y_{2}=1 \mid x, z\right)$ to replace $y_{2}$. In the original OLS estimation, $y_{2}$ is a binary variable, but $\hat{E}\left(y_{2}=1 \mid x, z\right)$ is a continuous variable. Does the difference between the two estimations is resulted from the different types of variables? We conduct an experiment to partly answer this question. A new binary variable of $\ddot{y}_{2}$ is constructed by the following way:

$$
\ddot{y}_{2}=1 \text { if } \hat{y}_{2}>0.5 ; \ddot{y}_{2}=0 \text { otherwise. }
$$

Then we estimate the OLS regression of the second step, except that we use $\ddot{y}_{2}$, rather than $\hat{y}_{2}$ as the instrument. The result is shown in Panel C of Table 2. We can see that the coefficients of the both variables are still very significant. The signs of both coefficients are still consistent with the prediction of the theory. As for the magnitude, the magnitude of the both coefficients is between the estimation in the simple OLS estimation and the IV regression. In other words, in the experiment regression, the coefficient of the sales dummy is larger than the estimation in the OLS regression and smaller than the estimation in the IV regression. Also, the coefficient of the log(price) is smaller than the estimation in the OLS regression and larger than the estimation in the IV regression. Thus we can conclude 
that the sharp contrast between the OLS estimation and the IV regression is partly due to the use of instrument variable and partly due to the different types of variables.

Table 2. Two-Step estimation

\begin{tabular}{|c|c|c|c|c|}
\hline \multicolumn{5}{|c|}{ Panel A: First-Step Probit regression } \\
\hline \multicolumn{5}{|c|}{ Dependent variable: sales dummy } \\
\hline & coef & Standard Error & p-value & R-Square \\
\hline $\log ($ price $)$ & -3.07 & 0.05 & 0.00 & \multirow{2}{*}{0.15} \\
\hline Unit cost in last week & 3.41 & 0.09 & 0.00 & \\
\hline \multicolumn{5}{|c|}{ Panel B: Second-Step OLS regression } \\
\hline \multicolumn{5}{|c|}{ Dependent variable: move (quantity sold) } \\
\hline & coef & Standard Error & p-value & R-Square \\
\hline$\underline{\log (\text { price })}$ & -387.11 & 17.42 & 0.00 & \multirow{2}{*}{0.21} \\
\hline$\hat{y}_{2}$ & 738.76 & 20.79 & 0.00 & \\
\hline \multicolumn{5}{|c|}{ Panel C: Second-Step OLS regression (experiment regression) } \\
\hline \multicolumn{5}{|c|}{ Dependent variable: move (quantity sold) } \\
\hline & coef & Standard Error & p-value & R-Square \\
\hline $\log ($ price $)$ & -658.00 & 12.90 & 0.00 & \multirow{2}{*}{0.21} \\
\hline$\ddot{y}_{2}$ & 469.02 & 11.88 & 0.00 & \\
\hline
\end{tabular}

First-step probit regression: $y_{2}^{*}=\gamma x+\delta z+v_{2}$;

Second-step OLS regression: $y_{1}=\beta x+\alpha \hat{y}_{2}+u_{1}$;

$y_{1}$ : move (quantity sold); $x$ : $\log$ (price), store dummy, week dummy; $y_{2}$ : sales dummy.

\subsection{Heckman Two-Step Estimation}

The selection problem may exist because we don't know whether sales stimulate quantity sold, or the retail sales are because that the retailer wants to stimulate consumers' purchases. To take the selection problem into account, the standard Heckman two-step estimation is applied to estimate the coefficients when there is a sale.

The result is shown in Table 3. Actually the result is very interesting. First, the coefficient of $\lambda$, inverse Mill's ratio, is very significant. It shows that the selection problem does exist. Second, the coefficient of $\log ($ price) is significant, and its scale is much larger than the estimation from the IV regression. Hence we may want to conclude that consumers are much more price sensitive when the product is on sale. The intuition behind the result from the Heckman estimation is not very clear. The theory predicts that people tend to purchase when they see the flag of "on sale". However this result shows that even the product is on sale, consumers are still very skeptical to the price. A plausible explanation to the finding in the Heckman two-step estimation is as follows. The product is on sale in roughly $1 / 3$ of the whole time period. Since the sales are very frequent, consumers always purchase it when it is on sale. They are insensitive to the price when the product is not on sale, because they don't even bother looking at the prices when they see there is no flag of sales. They just pass the shelf ignoring the product. Only when the product is on sale, they will begin to study the prices and decide whether they want to make a purchase and how much they want to buy. 
Table 3. Heckman Two-Step Estimation

\begin{tabular}{lcccc}
\hline & coef & Standard Error & p-value & R-Square \\
\hline $\log ($ price $)$ & -624.47 & 45.46 & 0.00 & \multirow{2}{*}{0.28} \\
\hline$\lambda$ & -183.48 & 24.57 & 0.00 & \\
\hline
\end{tabular}

First-step probit regression: $y_{2}^{*}=\gamma x+\delta z+v_{2}$;

Second-step OLS regression: $y_{1}=\beta x+\varphi \lambda+u_{2}$ if $y_{2}=1$;

$y_{1}$ : move (quantity sold); $x$ : log(price), store dummy, week dummy; $y_{2}$ : sales dummy

\subsection{Test for Robustness}

We are interested whether the result will change if we use price and price squared, instead of $\log (\mathrm{price})$, in all the above regressions. Thus, we just run three groups of regressions, which are the same as the previous regressions except we use price and price squared rather than $\log$ (price). Table 4 is the counterpart of Table 1 . The signs of the coefficients of price and price squared are correct. However, the sign of sales dummy is negative. It is counter-intuitive. This specification may have some problem.

Table 4. OLS regression

\begin{tabular}{lcccc}
\hline & coef & Standard Error & p-value & R-Square \\
\hline Price & -5847.89 & 79.31 & 0.00 & \\
\hline Price squared & 2835.14 & 43.67 & 0.00 & 0.24 \\
sales dummy & -16.61 & 5.31 & 0.00 & \\
\hline
\end{tabular}

OLS regression: $y_{1}=\beta x+\alpha y_{2}+u_{1}$;

$y_{1}$ : move (quantity sold); $x$ : price, price squared, store dummy, week dummy; $y_{2}$ : sales dummy.

Table 5 is the counterpart of Table 2. All the signs of coefficients are consistent with our intuition. All the coefficients of our interest are significant. The coefficient for price is negative; the coefficient for price squared is positive; and the coefficient for sales dummy is positive as well. However, the coefficient of the sales dummy is at a much smaller scale than the estimation in Table 2. In Table 2 it is 739, and in Table 5 it is 195 . The only difference between the two regressions is that we use different measure of price.

Table 5. Two-Step estimation

\begin{tabular}{|c|c|c|c|c|}
\hline \multicolumn{5}{|c|}{ Panel A: First-Step Probit regression } \\
\hline \multicolumn{5}{|c|}{ Dependent variable: sales dummy } \\
\hline & coef & Standard Error & $\mathrm{p}$-value & R-Square \\
\hline Price & -14.43 & 0.30 & 0.00 & \multirow{3}{*}{0.17} \\
\hline Price squared & 6.23 & 0.17 & 0.00 & \\
\hline Unit cost in last week & 3.41 & 0.09 & 0.00 & \\
\hline \multicolumn{5}{|c|}{ Panel B: Second-Step OLS regression } \\
\hline \multicolumn{5}{|c|}{ Dependent variable: move (quantity sold) } \\
\hline & coef & Standard Error & $\mathrm{p}$-value & R-Square \\
\hline Price & -4862.27 & 130.75 & 0.00 & \multirow{3}{*}{0.25} \\
\hline Price squared & 2361.02 & 66.26 & 0.00 & \\
\hline$\hat{y}_{2}$ & 195.11 & 23.81 & 0.00 & \\
\hline
\end{tabular}

First-step probit regression: $y_{2}^{*}=\gamma x+\delta z+v_{2}$;

Second-step OLS regression: $y_{1}=\beta x+\alpha \hat{y}_{2}+u_{1}$;

$y_{1}$ : move (quantity sold); $x$ : price, price squared store dummy, week dummy; $y_{2}$ : sales dummy. 
Table 6 is the counterpart of Table 3. Again all the coefficients are significant. The selection problem exists, and the signs of all coefficients are consistent with our intuition. Also, comparing the coefficients of price in Table 6 with that Table 5, we find that its magnitude slightly increases. This fact is consistent with the previous finding that people are even more prices sensitive when the product is on sale.

Table 6. Heckman Two-Step Estimation

\begin{tabular}{lcccc}
\hline & coef & Standard Error & p-value & R-Square \\
\hline Price & -5396.59 & 303.65 & 0.00 & \\
\cline { 1 - 4 } Price squared & 2500.89 & 149.89 & 0.00 & \multirow{2}{*}{0.31} \\
\cline { 1 - 4 }$\lambda$ & -67.09 & 28.63 & 0.00 & \\
\hline
\end{tabular}

First-step probit regression: $y_{2}^{*}=\gamma x+\delta z+v_{2}$;

Second-step OLS regression: $y_{1}=\beta x+\varphi \lambda+u_{2}$ if $y_{2}=1$;

$y_{1}$ : move (quantity sold); $x$ : price, price squared, store dummy, week dummy; $y_{2}$ : sales dummy

\subsection{Consumers Attitudes towards Price Increases and Decreases}

Table 7 shows the result of the regression of the residuals from the IV regression, namely abnormal change of demand, on dummies of price increases and price decreases. The main result is in column 1, and the estimations in subsamples are in column 2 and column 3.

Table 7. OLS regression

\begin{tabular}{lccc}
\hline & whole sample & on sale & not on sale \\
\hline$d_{\text {price up }}$ & 2.70 & 7.06 & 1.78 \\
\hline$p$-value & 0.44 & 0.57 & 0.56 \\
\hline$d_{\text {price down }}$ & 9.19 & 19.05 & 1.45 \\
\hline$p$-value & 0.01 & 0.04 & 0.71 \\
\hline
\end{tabular}

OLS regression: $\hat{u}_{1}=d_{\text {price up }}+d_{\text {price down }}+$ constant $+e$;

$\hat{u}_{1}$ : residuals from the IV regression in Table 2;

$d_{\text {price up }}$ and $d_{\text {price down }}$ : dummy variables denoting price increases and decreases respectively.

Interestingly, the first two columns show that people are much more aware of price decreases than price increases. The first column presents the result of the regression in the whole sample: the coefficient of the dummy denoting price decreases is positive and significant at $5 \%$ level, while the coefficient of the dummy denoting price increases is not significant at all. The first column presents the result of the regression in the subsample that product is on sale. Besides it confirms that people are more aware of price decreases than price increases, which we find in the whole sample, it also shows that people are much more sensitive to price decreases when the product is on sale. We can easily find out that the coefficient of the dummy denoting price decreases is 9.19 when we use the whole sample, and it is 19.04 when we just use the subsample that the product is on sale. This is consistent with the previous finding that people are more prices sensitive when the product is on sale. The third column shows that consumers are not aware of either price increases or price decreases when the product is not on sale. This finding is consistent with the previous finding that consumers will just ignore the product when they don't see a flag of sales.

This finding seems hard to explain. But we find that the mean of the changes of $\log$ (price) is 0.20 when price increases and mean of the changes of $\log$ (price) is 0.23 when price decreases. So the magnitude of price decreases is generally greater than the magnitude of price increases. Therefore, we have the following explanation to this finding. People are aware of price changes only when it reaches a certain limit. If the magnitude of price change is below this limit, then people will not be aware of it; if the magnitude of the price change is above the limit, then people will notice the change and adjust their quantity of consumption. The retailer practically knows the limit for the general 
population. When the retailer wants to increase the price, the price will increase by an amount just below the limit, and when the retailer wants to decrease the price, the price will decrease by an amount just above the limit. Hence the retailer takes advantage from consumers with this strategy.

\section{Conclusion and Discussion}

In this paper, we have three findings. First, we find that except price decreases, the signal of sales itself can largely stimulate consumers' purchases. The second finding is that consumers are more prices sensitive when the product is on sale than they are when the product is not on sale. The explanation to the second finding could be that consumers might just ignore the product when it is not on sale. The sales are so frequent that people just check at the price and buy the product when it is on sale. The third finding is that people are more aware of price decrease than price increase, even after we control for the effect of sales. This is because the magnitude of price decreases is generally larger than the magnitude of price increases.

There are several directions for future research. First, in the paper we just examine one product in one category in the DFF dataset. It would be interesting to check the robustness of the findings in this paper by applying the same method to other products in different categories. Second, although we can see a solid connection between the sales and quantity sold, we don't exactly know why. It could be because of the advertisement effect of sales, or people's emotion in playing a role. Therefore, if we can derive a game theoretical model between consumers and retailers, the empirical results would be more convincing. Third, in my opinion no theory with the assumption of rationality can be consistent with the third finding. Therefore, if one can put some behavioral factor in the model, it might be a new contribution to the literature.

\section{References}

Aguirregabiria, V. (1999). The dynamics of markups and inventories in retail firms. Review of Economic Studies, 66, 275-308. https://doi.org/10.1111/1467-937X.00088

Alvarez, et al. (2006). Sticky prices in the euro area: a summary of new micro evidence. Journal of the European Economic Association, 4, 575-584. https://doi.org/10.1162/jeea.2006.4.2-3.575

Barro, R. (1972). A theory of monopolistic price adjustment. Review of Economic Studies, 39, 17-26. https://doi.org/10.2307/2296440

Bils, M., \& P. Klenow. (2004). Some evidence on the importance of sticky prices. Journal of Political Economy, 112, 947-985. https://doi.org/10.1086/422559

Chevalier, J., A. Kashyap, \& P. Rossi. (2003). Why don't prices rise during periods of peak demand? evidence from scanner data. American Economic Review, 93, 15-37. https://doi.org/10.1257/000282803321455142

Fabiani, et al. (2005). The pricing behavior of firms in the euro area: new survey evidence. ECB Working Paper 535.

Golosov, M., \& R. Lucas. (2007). Menu costs and Phillips curves. Journal of Political Economy, 115, 171-199. https://doi.org/10.1086/512625

Magnani, J., A. Gorry, \& R. Oprea. (2016). Time and state dependence in an Ss decision experiment. American Economic Journal: Macroeconomics, 8, 285-310. https://doi.org/10.1257/mac.20130267

Nakamura, E., \& J. Steinsson. (2008). Five facts about prices: a reevaluation of menu cost models. Quarterly Journal of Economics, 123, 1415-1464. https://doi.org/10.1162/qjec.2008.123.4.1415

Rotemberg, J. (2008). Behavioral aspects of price setting, and their policy implications. NBER Working Paper No. 13754.

Sheshinski, E., \& Y. Weiss. (1977). Inflation and costs of price adjustment. Review of Economic Studies, 44, 287-303. https://doi.org/10.2307/2297067

Sheshinski, E., \& Y. Weiss. (1983). Optimum pricing policy under stochastic inflation. Review of Economic Studies, 50, 513-529. https://doi.org/10.2307/2297678

Varian, H. R. (1980). A model of sales. American Economic Review, 70, 651-659. 